\title{
Practice and Exploration of Mechanical Design Fundamental Experimental Teaching based on SPOC Qianqian $\mathrm{Lu}^{1, \mathrm{a}}$, Yangfang $\mathrm{Wu}^{1, \mathrm{~b}}$, Shuli Sun ${ }^{1, \mathrm{c}}$ \\ ${ }^{1}$ School of Engineering, Zhejiang University City College, Hangzhou, 310015, China \\ aluqianqian@zucc.edu.cn, bwuyf@zucc.edu.cn, 'sunsl@zucc.edu.cn
}

Keywords: Mechanical design fundamental experiment; SPOC; mixed teaching; teaching by learning.

\begin{abstract}
A new model of current internet teaching -SPOC (Small Private Online Course) is introduced by analyzing characteristics and problems of traditional mechanical design fundamental teaching system. This new model combines teaching through network, testing, homework and evaluation. The four parts work as one system by using both blackboard platform and classroom site to realize new mixed-teaching mode with network and classroom coexistence. During the teaching process students should carry out independent preview and fulfill test or quiz before class based on the experimental requirements within limited time. During experiment, student are provided with a video related with the experiment and do experiment as a group with 3 or 4 student according to guide book. Afterward, discuss topics and feedback projects are set for each experiment require students participating. This mixed-teaching mode motivates students' initiative, makes them the host of classroom to realize teaching by learning. By allowing students to engage in preparation ahead of class independently or corporately, that will help them review or preview theory related with the experiment they are going to do. It turns out that the students really help themselves and each other through SPOC.
\end{abstract}

\section{Introduction}

The course named mechanical design fundamental experiment, as a required one for all mechanical engineering students, has a close relationship with courses named mechanical principle and mechanical design, which places an important part in the whole course system that cannot be ignored. Experiment not only helps students to verify, to understand and grasp the theoretical teaching content but also cultivates students' innovation consciousness to solve the practical engineering problems and develops the ability of innovation and design capabilities [1]. At present, although this course has changed from traditional teaching by adding some innovative and comprehensive project, however, teaching means is still traditional with the activities of the teacher instructs and the students' acts [2]. This kind of teaching mode cannot stimulate students to participate in the experiment and interest in how the results come out. In addition, this class has limited class time, and limited experimental items, with assessment criteria unitary, making experimental class less attractive [3].Therefore, the reform of the experimental teaching mode is really necessary.

Massive Open Online Courses, short for "MOOC”, is a new educational model, has been popular all over the world since 2012. It shares the university courses all over the world through the Internet to meet people's desire to learn [4-6]. This new educational model is gradually being studied and practiced by the world's higher education workers. However, MOOC is not suitable for that kind of classes which has strong professional or experiment course has limited students. So, Small Private Online Course, short for "SPOC", as a new model develops from MOOC, is suitable for limit students, who are registrants. Besides of online video and exercises, there are auxiliary online and offline classroom for Q\&A, which have great significant for the revolution of college teaching reform. The reform of mechanical design fundamental experiment in our school is combing SPOC with classroom to effectively improve the teaching method. 


\section{The situation and problem of current mechanical design fundamental experiment}

\subsection{Situation of experimental teaching}

At present, the major colleges and universities have opened the corresponding experimental class associated with theory course. As the outstanding engineers plans promoted, the current experimental system has turned from validating and demonstrative to self-designed, comprehensive and innovative [7-9]. At present, our experimental teaching system is guided by the ability whose experiment items are comprehensive and the evaluation system is according to the whole performance and the write of scientific report, as shown in Fig. 1.



Fig. 1 The experimental items and evaluation system

The experimental course includes three levels of the experimental project:

(1) Establish an open perceptual knowledge experiment

The demonstration labs is open and supervised by senior student to help students studies on their own time on condition that they should finish all the work that is assigned. By this way, students will be more active and intiative. They will soon find experiment is estabilished on interest and enthusiasm not on task.

(2) Optimize the traditional experiment and keep some verification experiment

The traditional experiment class has certain advantages to form students engineering quality, such as, mechanism diagram drawing, shafting structure mapping and gear parameter measurement. These experiments help students to understand and master the basic theoretical knowledge. For some experiments, such as, gear parameter design, which can use computer software to aided design and by comparing with the results of experiment and theoretical calculations, students would have deeper understanding of design process and parameters.

(3) Add comprehensive and design experiments

Because of the course is the basic practice of the integration of mechanical principle and mechanical design. In order to combine the two theory course together, it is a great way to design a comprehensive experiment, as shown in Fig. 2. 


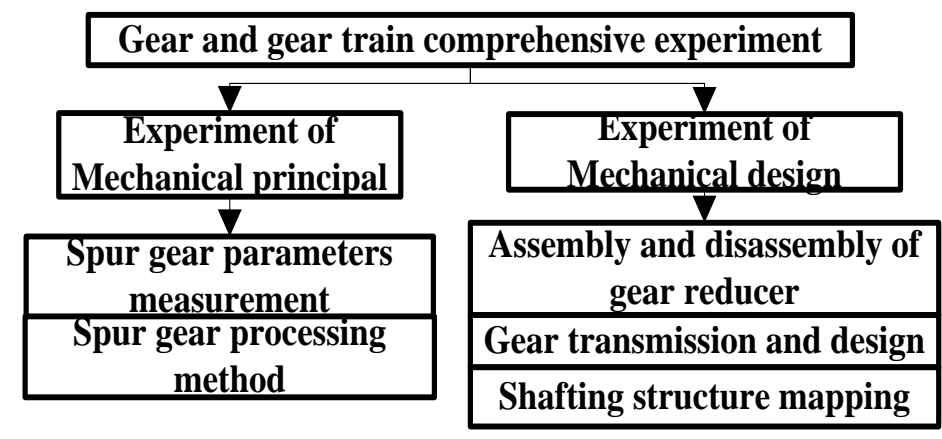

Fig. 2 Gear comprehensive experimental architecture

Fig. 2 shows how to combine the two theoretical courses. To design a whole mechnical system from design principle and structural design to gear wheel shaft design and gear train costs students a lot of preview work. So students will have a comprehensive understand of the gear and would have appropriate innovation design through this comprehensive experiment.

The new system encourages students to use a variety of methods in conducting with experiments, such as the use of computer aided software design, simulation, etc. As for innovative design items, students can design effective items according to the experimental equipment provided. In order to improve students' enthusiasm for experiment, it is supported for the students of self-designed experiment items and the appropriate platform will be built if needed.

\subsection{The characteristic of mechanical design fundamental experiment}

At present, our experimental system has been basically overcome the old practice teaching system in experiment course and the arrangement of items, however, there are the following reasons lead to experimental curriculum did not obtain the perfect effect.

(1) The teaching mode is also traditional which is difficult to improve the enthusiasm of the students. The experimental items prepared by the teachers before class, it seems that the experiment finishes as long as the experimental operation and report is completed without their active participation in the process.

(2) The experimental labs and equipment are insufficient. Some students cannot participate in the whole process because the equipment is limited. So, the phenomenon will be some students operate, and the rest of the students just stand by.

(3) Class time is fixed, it is hard to fully mobilize the rest of the after class time. And, each experimental item is relatively independent of the theoretical content which is modular and flexible due to the limitations of class.

The reform of the SPOC teaching concept, combined with the internet technology, helps students fully invest time and energy in practical courses on class or on their own time so as to truly achieve the initiative and the best results.

\section{Implementation of SPOC}

The basic process of small private online course (SPOC) is firstly teachers put the video materials related to the class on the internet, and assign homework to the students, secondly, it could figure out how much knowledge has been absorbed by students during the students' class performance, last but not the least, the teacher deals with work or other task together with students in classroom. In general, teacher can set and control the schedule if available and according to students' needs.

The structure of new SPOC teaching system used by our school is shown as Fig. 3.

According to the teaching concept of SPOC, these experimental items will be set according to Fig. 3. Before the class started, students need to complete test questions about the experiment item which is going to do, and watch operation video. During class, according to the experiment test tasks and experiment dos and don'ts to finish the experiment. Of course, this is the great opportunity for students and teacher to communicate about the item. After class, students should fulfill the experiment report according to the results and phenomenon. 
Course evaluation includes self-evaluation, mutual-evaluation and teacher-evaluation. The final result is comprehensive score associate with the quality of experimental report, discussion participation and the performance during experimental operation

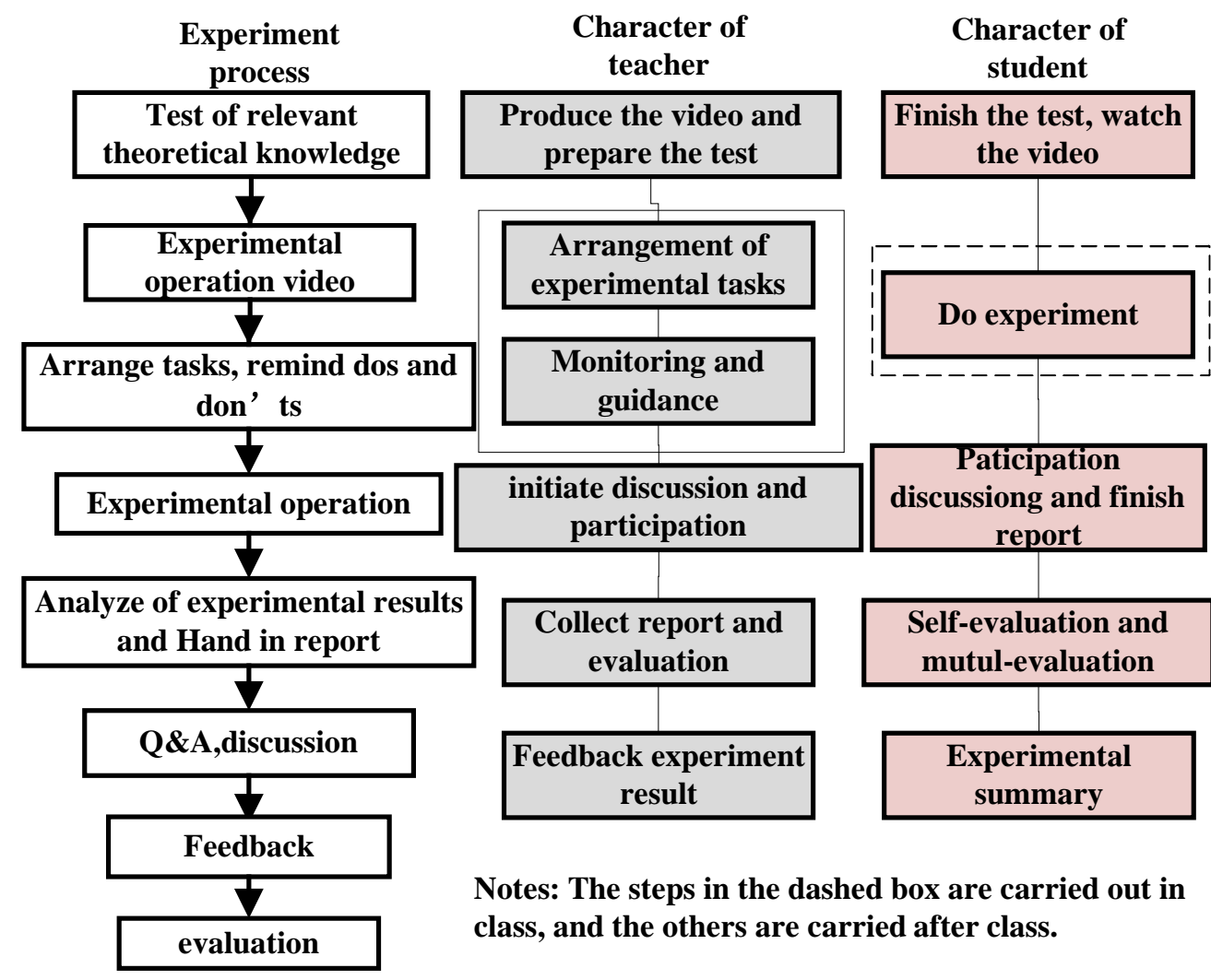

Fig. 3 Experimental system based on SPOC mixed teaching mode

\section{Typical example - experiment of belt transmission}

The reform combines with Blackboard platform based on SPOC teaching mode to realize the sharing of network resources, table 1 is an execution list of belt transmission experiment, including the experimental process, specific content and the realization form of every step.

Table 1. Execution list of belt transmission experiment

\begin{tabular}{|c|c|c|}
\hline \multicolumn{3}{|c|}{ Experiment item of belt transmission } \\
\hline Procedure & Content & Implementation \\
\hline Test & 5 choice questions and 5 judgment question & BB-Test[before class] \\
\hline Watch video & Introduces the basic experiment and the experiment & BB-Course \\
\hline About 4min & $\begin{array}{l}\text { equipment, as well as the requirements of the } \\
\text { experiment operation and recording parameters. }\end{array}$ & [before class] \\
\hline Requirements & According to recording da & Oper \\
\hline & $\begin{array}{l}\text { and slip curve at different initial tension (at least } 2 \\
\text { kind) }\end{array}$ & $\begin{array}{l}\text { BB-homework:result } \\
\text { upload[in class] }\end{array}$ \\
\hline Discussion & The effect of initial tension on & BB-discussion-Belt \\
\hline & $\begin{array}{l}\text { Factors that affect the initial tension? How to prevent } \\
\text { slipping? etc. }\end{array}$ & fter class] \\
\hline $\begin{array}{l}\text { self-evaluation, } \\
\text { mutual-evaluation }\end{array}$ & $\begin{array}{l}\text { Each student scores himself and the other four to six } \\
\text { students' reports. }\end{array}$ & $\begin{array}{l}\text { BB-Evaluation Standard } \\
\text { [after class] }\end{array}$ \\
\hline teacher-evaluation & $\begin{array}{l}\text { Teachers evaluate the report and give students a } \\
\text { grade, and then comprehensive the above score to get } \\
\text { the weighted average scores. }\end{array}$ & $\begin{array}{l}\text { BB-Achievement Center } \\
\text { [after class] }\end{array}$ \\
\hline Score & $\begin{array}{l}\text { According to the participation of the discussion } \\
\text { board, the performance of the operation and the score } \\
\text { of report comes out the final score. }\end{array}$ & $\begin{array}{ll}\text { Statistics by } & \text { teaching } \\
\text { assistants and } & \text { teachers } \\
\text { [after class] } & \end{array}$ \\
\hline
\end{tabular}




\section{Conclusion}

The new reform of mechanical design fundamental experiment combines SPOC network and classroom to realize each student participant in every experiment items. Through pre-class test, students can truly combine the theory with practice. They also develop self-learning ability by watch video and operate on their own. Also, the students' valuation includes their self-evaluation, mutual-evaluation which help themselves to tell what they are miss during the theory class and experimental class. Students and teacher will learn from each other and improve together through discussion and feedback as well as helps teaching reform perfect. In a word, during the whole teaching process, the reform is truly put the students as the leading actor in the classroom, that's why how the teaching effect get promoted and improved.

\section{Acknowledgment}

This paper is supported by the 8th key courses construction fund of Zhejiang University City College (SJ1503).

\section{References}

[1] Y. YANG, P. XI, Y.R. ZHANG. Strengthing quality, facing creation, constructing experiment teaching system of mechanical foundation[J]. Experimental Technology and Management, 2008, 25(1):11-15.(In Chinese)

[2] Z.C. ZHU, Y. WANG, J.Y. XIE. Reflections on Experimental Teaching of Fundamentals of Mechanical Design[J]. RESEARCH AND EXPLORATION IN LABORATORY, 2013, 05: 146-149. (In Chinese)

[3] Y. JIN, P.L. YANG, CHEN Xiao-nan. Practice and Exploration on Experimental Teaching of Basic Machinery[J]. RESEARCH AND EXPLORATION IN LABORATORY, 2014, 09: 231-235. (In Chinese)

[4] Y.Q.Kang. An analysis on SPOC: Post-MOOC era of Online Education[J]. TSINGHUA Journal Of Education, 2014,01:85-93. (In Chinese)

[5] R. Chen, C. Yang. Blended Learning for SPOC[J]. DISTANCE EDUCATION IN CHINA, 2015,05:42-47+67+80. (In Chinese)

[6] H.D. YIN. Exploration of Blended Teaching Model based on Fanya SPOC Platform during the Post-MOOC Period[J]. Modern Educational Technology, 2015,11:53-59. (In Chinese)

[7] J.M. ZHAI, X. PING, P. HUANG, etc. Design and construction of remote experimental platform on mechanical basis[J]. Experimental Technology and Management, 2012, 29(4): 84-89. (In Chinese)

[8] K.Y. Tang, Z.Y. Wang, L. Song. Reformation and Exploration of Mechanical Design Experiment Teaching[J].China Educational Technology \& Equipment, 2011,9(27):118-120. (In Chinese)

[9] E ZHANG, Teaching reform and exploration of "mechanical design foundation" course in Applied Undergraduate Colleges[J].EDUCATION TEACHING FORUM, 2015, (13): 120-122. (In Chinese) 